To the Editors:

\title{
Unacceptable variance in the estimation of plasma concentration of paracetamol
}

Plasma paracetamol level is used as a clinical tool for prediction of persons at risk of hepatotoxicity and need for antidote treatment in acute paracetamol poisoning. This facility is unavailable in the National Hospital of Sri Lanka. Therefore tests are done in different laboratories. We calculated trueness and intra-assay and inter-assay variability as a coefficient of variability (CV) in three commercial laboratories (A, B and C) and two academic laboratories (D and $\mathrm{E}$ ) to determine the reliability of the assay results produced in different laboratories,

Trueness is a measure for the closeness of agreement between the true value and the value obtained by applying the test procedure a number of times [1]. It is assessed using samples spiked at least in three different concentration levels (low, medium and high) and is expressed as a percentage [1]. A variation of $\pm 20 \%$ at the lowest calibration point and $\pm 15 \%$ for higher concentrations are regarded as acceptable [1]. CV is the standard deviation divided by mean and is expressed as a percentage. A CV less than $20 \%$ is considered acceptable [2].

The stock solution of paracetamol was prepared in blank plasma. Three clinically relevant strengths (40 mg/l, $75 \mathrm{mg} / \mathrm{l}$ and $140 \mathrm{mg} / \mathrm{l}$ ) were prepared in blank plasma using the stock sample and were sent for analysis to the five laboratories. All analysts were blinded to the strength of the samples. The procedure was repeated after three days.

The assay results of 5 laboratories, percentage deviation, intra-assay and inter-assay variability and cost/ per test are shown in the Table.

The inter-assay variability ranged widely among all laboratories. However, the paracetamol concentrations obtained at academic laboratories ( $\mathrm{D}$ and $\mathrm{E}$ ) were within the trueness limit, intra-assay variability and inter-assay variability. Cost per test was highest at the laboratory C, although the results produced at this laboratory were not within the acceptable trueness limits. Paracetamol concentrations estimated at laboratory B also were not within the limits of trueness and intra-assay variability. Furthermore laboratory B had a very high percentage deviation (1650\%) for the low concentration in day 1 which is likely due to a methodological error.

The results of this study indicate that there are wide variations in plasma paracetamol concentrations estimated at different laboratories for a given sample. This is unacceptable given that it is critical for both therapeutic decisions and outcome. We conclude that the laboratories should carry out regular calibration of instruments and validation of methods. Laboratories often claim accreditation, but it is the responsibility of the health professionals who request tests from laboratories to see that the respective laboratories are accredited for each test method they perform.

\section{(See Table on next page)}

\section{Financial support}

South Asian Clinical Toxicology Research Collaboration funded by the Wellcome Trust/National Health and Medical Research Council International Collaborative Research Grant GR071669MA.

\section{References}

1. Moffat AC, Osselton MD, Widdop B. eds. Clarke's Analysis of drugs and poisons, 6th edition, London: Pharmaceutical press, 2006.

2. Reed GF, Lynn F, Meade BD. Use of coefficient of variation in assessing variability of quantitative assays. Clinical and Diagnostic Laboratory Immunology 2002; 9: 1235-9.

\section{S M D K Ganga Senarathna ${ }^{1}$, S Sri Ranganathan ${ }^{1}$, A H Dawson ${ }^{2}$ and B M R Fernandopulle ${ }^{1}$}

${ }^{1}$ Department of Pharmacology, Faculty of Medicine, University of Colombo, Sri Lanka,

${ }^{2}$ South Asian Clinical Toxicology Research Collaboration, Sri Lanka.

Correspondence: SMDKGS, e-mail <ganga136@hotmail.com>. Received 30 July and revised version accepted 27 October 2009. Competing interests: none declared. 


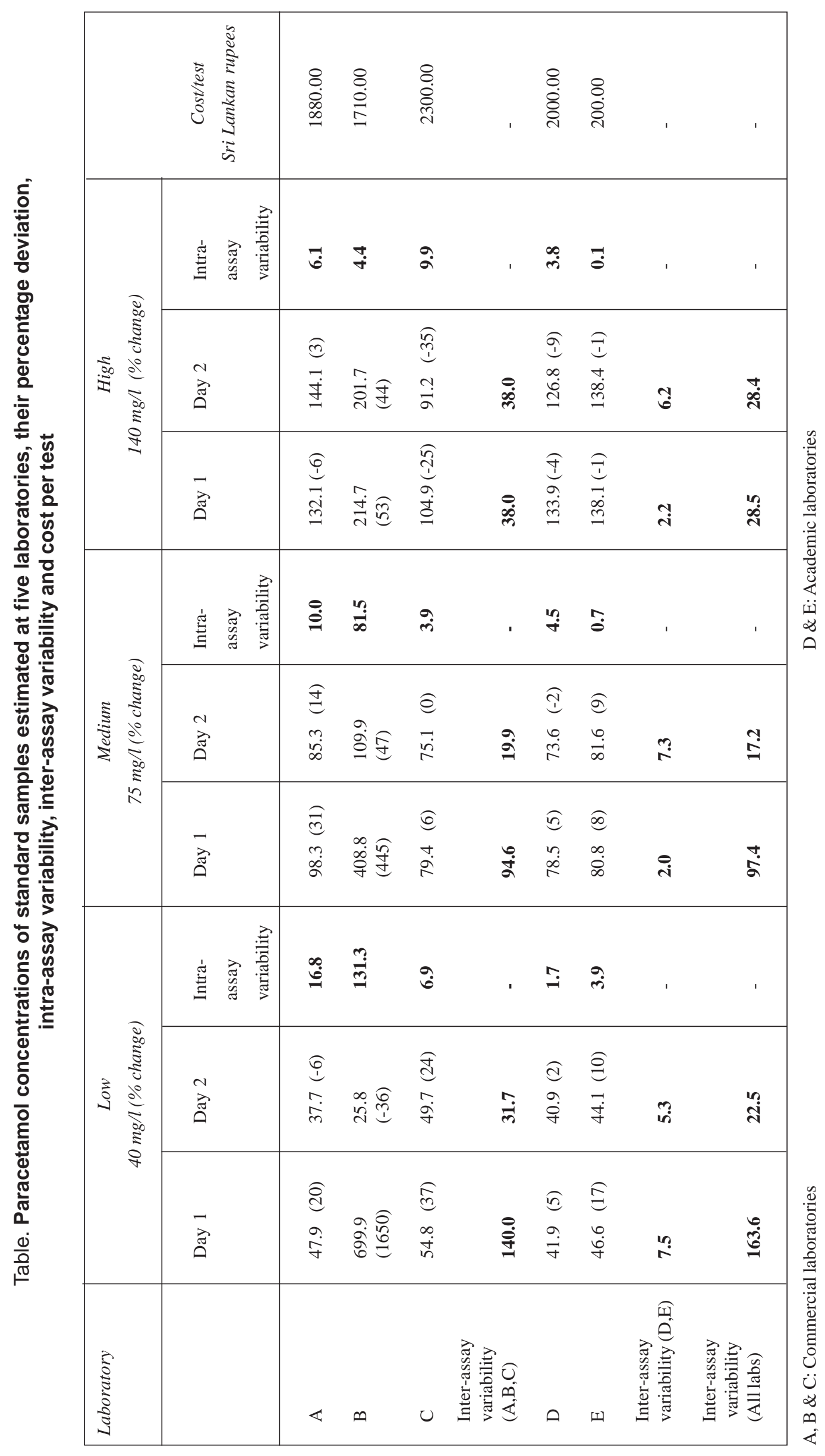

